\title{
DAVIS, ANgela. Mulheres, RaÇa E Classe. TraduÇão de Heci Regina Candiani. São Paulo: Boitempo, 2016, 244P.
}

\author{
Aléxia Bretas $^{1}$
}

Quase quatro décadas depois de sua publicação original, Mulheres, raça e classe (2016) segue informando, teórica e praticamente, os feminismos e, em especial, o feminismo negro brasileiro -, a despeito de sua irredutível heterogeneidade. Sua autora é Angela Davis, uma das mulheres mais proeminentes, não apenas para os estudos interseccionais, mas também para os movimentos sociais que buscam combater, na prática, as estruturas gerativas das assimetrias de gênero, raça e classe, em todas as suas formas. Nascida no Alabama, em 1944, Angela Yvonne Davis é ex-aluna do filósofo Herbert Marcuse, em Brandeis, professora emérita do Departamento de Estudos Feministas da Universidade da Califórnia em Santa Cruz, e ícone maior da luta pelos direitos civis, pelo feminismo dos $99 \%$, pela aboliçáa da pena de morte, contra o encarceramento em massa da populaçáo negra e a violência policial contra latinos e afrodescendentes pobres.

Publicado pela primeira vez em 1981, Mulheres, raça e classe reúne treze ensaios cuidadosamente redigidos, a fim de fundamentar as origens das lutas feministas e antirracistas em bases materialistas e dialéticas. Contudo, a despeito dos imprescindíveis conteúdos históricos presentes no livro, trata-se de um trabalho tanto de pesquisa documental quanto de experiência vivida, as-

${ }_{1}^{1}$ Professora de Filosofia na Universidade Federal do ABC (UFABC), São Bernardo do Campo, SP Brasil. (DD https://orcid.org/0000-0002-5447-0003 E-mail: alexia.bretas@ufabc.edu.br

Filósofa com Mestrado e Doutorado pela USP e Pós-Doutorado em Teoria Literária pela Unicamp. Autora dos livros A constelação do sonho em Walter Benjamin (Humanitas, 2008), Do romance de artista à permanência da arte (Annablume, 2013) e Fantasmagorias da modernidade (Ed. Unifesp, 2017).

http://dx.doi.org/10.1590/0101-3173.2019.v42n2.12.p235 
sinada por essa incansável pensadora e ativista já filiada ao Partido Comunista dos Estados Unidos e membro do Partido dos Panteras Negras (Black Panther Party). Confirmando sua vocação combativa das injustiças sociais em todo o mundo, bem como seu vínculo duradouro e afetivo com o movimento negro, no Brasil, Angela Davis esteve no país, em 1997, para participar da $1^{\text {a }}$ Jornada Cultural Lélia Gonzales, em São Luís do Maranhão, retornando em 2017, para celebrar o Dia da Mulher Negra Latina e Caribenha, no Julho das Pretas, em Salvador. Nessa ocasiáo, ela reconheceu a importante atuaçáo das mulheres negras brasileiras em lutas históricas e contemporâneas pela liberdade, vislumbrando, nesse aprendizado coletivo, nada menos que "o futuro do planeta".

Desse modo, com tradução de Heci Regina Candiani, orelha de Rosane Borges e prefácio de Djamila Ribeiro, Mulheres, raça e classe aporta em boas mãos e em boa hora, para se entender os múltiplos efeitos da interseccionalidade entre os marcadores de classe, raça e sexualidade para além de reificaçóes e sectarismos, dentro e fora da academia. Sendo o primeiro de outros três lançamentos publicados pela editora Boitempo - a saber, Mulheres, cultura $e$ politica (2017), A liberdade é uma luta constante (2018) e Uma autobiografia (2019) -, o livro articula elementos fundamentais para potenciar insights valiosos trazidos pela segunda onda do feminismo - sobretudo nos dias atuais, diante da chamada reação conservadora.

Apontando a singularidade da postura, a um só tempo, acadêmica e militante de Angela Davis, Djamila Ribeiro destaca a rigorosa lucidez dessa autora marxista - e, apesar disso, crítica de uma certa esquerda dogmática, insistentemente alheia a suas próprias nuances, insuficiências e contradiçóes internas:

A recusa a um olhar ortodoxo mantém Davis atenta às questóes
contemporâneas, que abarcam desde a cantora Beyoncé à crise de
representatividade. A discussão feita por ela sobre representação foge de
dicotomias estéreis e nos auxilia numa nova compreensão. Acredita que
representação é importante, sobretudo no que diz respeito à população
negra, ainda majoritariamente fora de espaços de poder. No entanto, tal
importância não pode significar a incompreensáo de seus limites. Para além
de simplesmente ocupar espaços, é necessário um real comprometimento
em romper com lógicas opressoras. (RIBEIRO apud DAVIS, 2016, p. 13).

Assim, dedicada à tarefa de compreender, para poder, de fato, "romper com lógicas opressoras", Angela Davis examina questóes que permanecem problemáticas, não obstante a distância cronológica que nos separa dos anos 
quando foram inicialmente tematizadas. Nesse sentido, Davis oferece não apenas um acurado diagnóstico histórico-materialista das opressóes antinegras sofridas ao longo de todo o processo de formação dos EUA, como ainda procura valorizar alternativas e práticas de resistência fomentadas nos espaços de aprendizado, solidariedade e luta política, dentro e fora do país. Com esse intuito, o movimento antiescravagista, a campanha pelo sufrágio feminino, os movimentos operários e trabalhistas são apresentados e discutidos com fôlego historiográfico e rigor científico dignos de elogios.

Além disso, ao refletir sobre seus limites e perspectivas concretas, a autora não hesita em discutir questóes complexas, as quais muitas vezes excedem o âmbito da ação política propriamente dita, vindo a afetar a esfera privada e mesmo íntima, como no caso do trabalho doméstico, dos direitos sexuais e reprodutivos, e da importância da educação para uma efetiva libertação do ciclo de dominação sistêmica retroalimentada pela reprodução ampliada do capital, em todas as suas formas. Por sinal, conforme o próprio título da obra anuncia, um dos grandes méritos de Mulheres, raça e classe é precisamente colocar em evidência os modos pelos quais as opressôes entrelaçadas de gênero e raça, bem como aquelas derivadas da exploração e/ou precarização do trabalho, incidem sobre as subjetividades e os corpos das mulheres negras. Outro aspecto não menos importante para o reconhecimento das inequívocas realizaçóes desse volume é a apresentação das estórias de vida e de luta de tantas e tão notáveis figuras femininas negras ou comprometidas com a causa da justiça social; mulheres fortes, corajosas e altivas, via de regra silenciadas, ignoradas e/ou falsamente reconhecidas pelos documentos da história oficial. Finalmente, para além de maniqueísmos vulgares, vitimismos inoperantes e jargóes ininteligíveis, Angela Davis sustenta um olhar sensível tanto para as dificuldades quanto para as possíveis alianças que florescem ali precisamente onde o solo aparenta ser menos propício - como no caso da amizade entre Elizabeth Gurley Flynn e Claudia Jones, enquanto estiveram presas na Casa de Detenção Feminina de Nova York e no Reformatório Federal Feminino de Alderson.

\section{O Legado Da ESCRAVIDÁo}

Conforme a própria trajetória acadêmica e pessoal da autora deixa patente, a luta pela libertaçáo assoma como um desafio renovado e um compromisso constante em sua vida. "Libertem Angela Davis e todos os prisioneiros políticos" foi, a propósito, o mote da campanha internacional em prol da 
soltura daquela que, em 1970, fora perseguida e encarcerada durante quase um ano e meio, como uma das dez pessoas mais perigosas do país, segundo o FBI. A liberdade para ela nunca fora, portanto, mera categoria filosófica ou expressão retórica, apenas. Ao contrário de colegas que, em nome de um posicionamento político dito "isento", exaltam uma liberdade abstrata, vazia e desencarnada, apenas em teoria, Angela Davis busca defender e lutar pelas condiçôes de possibilidade de sua realização concreta, em especial, entre coletividades, de um modo ou de outro, submetidas à maximização de sua condição precária - como mulheres, negros, latinos e pobres. Mediante o recurso a uma certa dialética da libertação, ela parte de uma consistente análise crítica do duradouro legado histórico da escravidão, sobretudo, para a reconfiguração do que se refere como uma nova condiçáo da mulher.

Distinguindo sua abordagem interseccional da de tantos outros historiadores contemporâneos, como Ulrich B. Phillips e Herbert Aptheker, a autora se detém nas especificidades mesmas da situação das "mulheres de cor", desenvolvendo sua argumentação para além dos propalados estereótipos, que insistem em marcar a sofrida realidade das escravas negras com os estigmas, seja de uma incorrigível "promiscuidade sexual”, seja de seus igualmente questionáveis "pendores matriarcais". Empenhada em desmontar tal dispositivo de dominação econômica, política e cultural, Davis demonstra, com riqueza de fontes documentais e uma penetrante análise histórica, a relação indelével entre os marcadores sociais de raça e de gênero e a exploração do trabalho escravo, nos Estados Unidos - principalmente na cultura do algodáo, do tabaco, da cana-de-açúcar, nas minas de carvão e nas fundiçôes de ferro, mas também nas mais variadas atividades domésticas usualmente realizadas por pessoas negras.

Nesse contexto, ela chama particular atenção à precária condição das mulheres de origem africana: como negras, as escravas eram submetidas a todo tipo de práticas disciplinares e punitivas, por exemplo, com chibatadas, privaçôes e mutilações. Além disso, como mulheres, estavam suscetíveis a estupros e abusos sexuais cotidianos, como parte do expediente de apropriaçáo material e econômica de seus corpos, levada a termo por seus possuidores legais. Como a autora observa, quando era lucrativo explorá-las como se fossem homens, as escravas eram tratadas como se não possuíssem um gênero (genderless), sendo alocadas para realizar os serviços mais árduos, degradantes e penosos. Não obstante, quando elas podiam ser exploradas, punidas e reprimidas de formas cabíveis somente às mulheres, elas permaneciam compulsoriamente reféns de suas funçôes "naturais" de "fêmeas". 
Assim, quando o tráfico negreiro foi proibido nos Estados Unidos, os grandes latifundiários se empenharam de todas as maneiras para aumentar sua população "doméstica" de trabalhadores compulsórios. Desse modo, as escravas eram forçadas a ter dez, quatorze ou até dezoito filhos, sendo valorizadas ou sumariamente desvalorizadas - de acordo com sua capacidade reprodutiva. Ainda assim, não eram consideradas "mães", senão "procriadoras" (breeders) - meros animais de criação, cujo valor de uso podia ser calculado precisamente em termos de sua condição de multiplicar a mão de obra de seus proprietários.

\section{EDUCAÇÃo E LIBERTAÇÁo}

No entanto, depois de um quarto de século do fim dessa "peculiar instituição", um contingente expressivo de mulheres ainda trabalhava em áreas rurais. Aquelas que conseguiram galgar os degraus da casa grande não puderam, contudo, seguir adiante em seu percurso. Davis observa que apenas um número infinitesimal de mulheres negras conseguiu escapar do campo, da cozinha ou da lavanderia. Se, em 1899, 60\% da mão de obra negra no estado da Pensilvânia estava empregada em algum tipo de função doméstica, a situação das trabalhadoras negras era ainda mais dramática: nada menos que $91 \%$ delas estavam contratadas como serviçais. Aquelas poucas que chegaram a lecionar em escolas acabaram sendo demitidas em função do preconceito e da repressão racial. Chamando atenção para o "modo intrincado" através do qual o racismo opera, a autora destaca o depoimento de algumas empregadoras brancas que acreditavam estar contribuindo para a remissão da imagem pejorativa associada às "mulheres de cor", reafirmando que eram, de fato, "honestas", "limpas" e "cuidadosas". Entretanto, ao sustentar que não apenas aprovavam como ainda preferiam que o trabalho doméstico fosse realizado por pessoas negras, em detrimento das brancas, tais senhoras acabavam reforçando os estereótipos da mulher negra como empregada naturalmente resistente, dócil e confiável. Conforme Davis pondera, "a definição tautológica de pessoas negras como serviçais é, de fato, um dos artifícios essenciais da ideologia racista." (DAVIS, 2016, p. 102).

Para impedir seu avanço e combater a proliferação de seus discursos, mesmo após o fim oficial do trabalho escravo, pelo menos quatro milhóes de pessoas alforriadas já haviam se dado conta de que "o conhecimento torna uma criança inadequada para a escravidão." (DOUGLASS apud DAVIS, 2016, p. 108). Entre elas, o menino Frederick Douglass, desde muito cedo, 
demostrara uma "ânsia profunda pelo saber", procurando aperfeiçoar seu talento para a escrita e, assim, continuar em segredo a busca por uma formação educacional que, mais tarde, o tornaria um dos mais brilhantes pensadores, escritores e oradores na luta contra o racismo antinegro no século XIX. Sua vida e obra confirmam não só a importância da educação como forma de resistência contra a opressão racial, como também desmistificam a falsa crença de que os negros seriam biologicamente despreparados e, portanto, inteiramente ineptos a realizar todo e qualquer tipo de atividade intelectual:

Com frequência, os poderes mistificadores do racismo emanam de sua lógica irracional e confusa. De acordo com a ideologia dominante, a população negra era supostamente incapaz de progressos intelectuais. Afinal, essas pessoas haviam sido propriedade, naturalmente inferiores quando comparadas ao epítome branco da humanidade. Mas, se fossem realmente inferiores em termos biológicos, as pessoas negras nunca teriam manifestado desejo nem capacidade de adquirir conhecimento. Portanto, náo teria sido necessário proibi-las de aprender. Na realidade, é claro, a populaçáo negra sempre demonstrou uma impaciência feroz no que se refere à aquisição de educaçáo. (DOUGLASS apud DAVIS, 2016, p. 108).

Exemplo de coragem, perseverança e determinação, o nome de Myrtilla Miner é indissociável da luta de milhares de negras e negros pelo direito à educação. Considerado inicialmente temerário inclusive por Frederick Douglass, seu grande projeto era a fundação de uma faculdade para professoras negras. A despeito dos sérios riscos que correu, por conta de sua ousadia, a Escola Miner de Formação de Professoras foi inaugurada em outubro de 1851, no distrito de Columbia - na época, um dos redutos mais conservadores do poder escravagista nas Américas. Malgrado a luta de sua diretora para ensinar, e de suas alunas para aprender, foram inúmeros os ataques sofridos por todas elas, seja na forma de despejos e tentativas de incêndio, seja na de crimes cometidos por grupos racistas armados.

Como Angela Davis faz notar, as pessoas negras que se beneficiavam com o acesso à instrução acadêmica necessariamente vinculavam a aquisição de conhecimento à luta maior de seu povo pela liberdade de agir e pensar. Não é, pois, por mera coincidência histórica que um número expressivo de mulheres brancas que defendiam suas irmãs negras, em diversas situações perigosas - entre as quais se conta a própria Myrtilla Miner -, estavam também visceralmente engajadas na batalha longa e diária pelo direito irrestrito à educaçáo. 
Assim, "como professoras, as mulheres negras e brancas parecem ter desenvolvido uma profunda e intensa admiração mútua. [...] A união e a solidariedade entre elas ratificaram e eternizaram uma das promessas mais férteis de nossa história." (DAVIS, 2016, p. 115-116).

\section{“Primeiro A MUlher, POR ÚlTimo O Negro"}

Apesar disso, o racismo logrou perseverar mesmo dentro de grupos considerados progressistas, como o efervescente movimento pelo sufrágio feminino - apenas parte do qual se colocava a favor dos direitos das populaçôes afrodescendentes e afrodiaspóricas. Emblemático dessa divisão interna é o diálogo travado entre Susan B. Anthony e Ida B. Wells - esta última, aliás, fundadora da primeira associação de sufragistas negras, nas Américas. A admiração da segunda pela primeira esbarrava, contudo, na omissão pública de Anthony com relação ao direito de voto inclusive para as mulheres negras. Justificando sua conduta, essa pioneira e veterana do movimento sufragista se defendia, alegando que, caso a Associação Nacional Estadunidense pelo Sufrágio Feminino passasse a aceitar também integrantes negras, ela corria o risco de ser esvaziada pelas mulheres brancas sulistas contrárias a tal decisão. Malgrado o profundo respeito pela campanha de sua "irmã branca" em prol dos direitos das mulheres, Wells, no entanto, era bastante incisiva ao criticar a postura, no mínimo, "ambivalente" da colega, a qual só fazia contribuir para a reafirmação da atitude segregacionista por parte das mulheres brancas da classe média e da burguesia.

Essa tendência ascendente seria claramente ratificada pelo recrudescimento de práticas e políticas públicas contrárias à inclusáo social, oficializadas, entre 1888 e 1890 , por estatutos e emendas constitucionais, as quais legalizavam a segregação racial, em particular, no estado do Mississipi - inclusive privando sua numerosa população negra do imprescindível direito ao voto. Em face da escalada de violência disparada pelos frequentes assassinatos e linchamentos que proliferavam virulentamente, nos estados do Sul, Ida B. Wells irá condenar energicamente a imperdoável omissão da igreja, da imprensa e de boa parte dos cidadáos brancos que ainda insistiam em manter-se "neutros" diante dos reincidentes ataques, os quais ameaçavam a liberdade, a segurança e a própria vida de centenas de milhares de homens, mulheres e crianças negras, em diversos estados: 
Nos últimos dez anos, mais de mil homens, mulheres e crianças negras sofreram mortes violentas pelas mãos de uma gangue branca. E o restante dos Estados Unidos ficou em silêncio. [...] O clero e a imprensa de nosso país permanecem em silêncio diante dessas seguidas atrocidades, e a voz da minha raça, torturada e ultrajada dessa forma, é reprimida ou ignorada em qualquer lugar dos Estados Unidos onde ela se levante para exigir justiça. (WELLS apud DAVIS, 2016, p. 120).

A fim de solucionar a tão controvertida "questão de cor", nos Estados Unidos, a proposta de Henry Blackwell era táo simplória quanto infame: “adotar o sufrágio feminino como uma solução ao problema do negro". Desse modo, um dos mais atuantes fundadores do partido republicano buscava persuadir a populaçáo do Sul de que o voto das mulheres brancas era extremamente vantajoso à causa anglo-saxã. "Se o sufrágio feminino for aprovado, atrairemos para nossas fronteiras pessoas de caráter e posição, com recursos e educação. [...] Quem hesitaria ao escolher entre as mulheres instruídas e os negros ignorantes?" Como Angela Davis é certeira em observar, enquanto por anos e anos as líderes sufragistas haviam justificado sua indiferença pela pauta da paridade étnico-racial, valendo-se do argumento tático da conveniência, a partir da virada do século, o sufrágio feminino passou a ser defendido como o meio mais eficaz de se alcançar a reconciliação entre Norte e Sul, pela via da segregação racial. Assim, não eram os direitos civis ou a igualdade política das mulheres que moviam a defesa do voto feminino, senáo a necessidade de garantir a superioridade racial da população branca diante da "ameaça africana" ao desenvolvimento soberano da nação.

\section{TENSÓES E COLABORAÇÓES INTER-RACIAIS}

Em consequência, a cooptação do movimento sufragista pelos interesses do grande capital monopolista torna premente o desmanche da articulação espúria forjada entre o ideal da supremacia racial e a hegemonia imperialista do Ocidente. Não é, pois, acidental que Angela Davis dedique boa parte de sua pesquisa à análise da situação das mulheres trabalhadoras, assim como à importância da luta de figuras como Lucy Parsons, Ella Reeve Bloor, Anita Whitney, Elizabeth Gurley Flynn e Claudia Jones pela causa comunista. Se a constituição das organizaçóes e sindicatos socialistas, durante toda a segunda metade do século XIX, deu-se quase que exclusivamente sem a participaçáo efetiva de mulheres, a partir de 1900, a composição do movimento socialista 
começava a mudar, contando, cada vez mais, com mulheres operárias atraídas pelo desafio de tomar parte nessa cruzada contra as opressóes de classe. Contudo, como Davis ressalta, a negligência do partido socialista em relação às mulheres negras era um dos legados infelizes que o Partido Comunista ainda teria de superar.

Emblemático desse desafio maior, o encontro entre as ativistas Elizabeth Gurley Flynn e Claudia Jones indica o árduo caminho que ambas deveriam trilhar até que a causa da igualdade sexual e racial fosse, de fato, estabelecida na prática concreta de milhôes de cidadãs e cidadáos atingidos pelas disparidades econômicas e sociais. Filha de membros do Partido Socialista, aquela primeira descobriria, desde muito cedo, sua aguerrida disposição para engajar-se na luta contra as crescentes desigualdades materiais e simbólicas produzidas pelo modus operandi do sistema capitalista. Tanto que, aos dezesseis anos apenas, a jovem Elizabeth realizaria sua primeira aparição pública junto à Agremiação Socialista do Harlem, sendo seu discurso inaugural baseado nos livros Reivindicação dos direitos da mulher, de Mary Wollstonecraft, e Mulheres e socialismo, de August Bebel. Responsável pelo lançamento de sua fulgurante carreira como ativista, o título de seu discurso seria, a propósito, bastante revelador de seu percurso político a partir de então: "O que o socialismo fará pelas mulheres." Já em uma assembleia de greve entre trabalhadores e trabalhadoras do setor têxtil, em 1912, Mary Heaton Vorse, que cobria o evento pela Harper's Weekly, comenta suas impressóes sobre a presença e os efeitos de sua carismática líder comunista:

Quando Elizabeth Gurley Flynn falou, o entusiasmo da multidão se tornou visível. Ela ficou ali, jovem, com os seus olhos azuis irlandeses, seu rosto branco como magnólia e sua nuvem de cabelos negros, o retrato de uma jovem líder revolucionária. Ela emocionou a todos, elevou-lhes o ânimo em seu apelo por solidariedade. [...] Foi como se uma chama tivesse arrebatado a audiência, algo emocionante e poderoso, um sentimento que havia tornado a libertação do povo algo possível. (VORSE apud DAVIS, 2016, p. 167).

Em suas frequentes viagens pelos Estados Unidos como agitadora de greves, Flynn às vezes trabalhava com o conhecido líder indígena Frank Little. Certo dia, arrancado do hotel onde passava a noite, depois de discursar para a mão de obra mineira de uma companhia de extração de ferro em Montana, Frank Little foi brutalmente conduzido e enforcado entre as vigas de sustentação da ferrovia, nas cercanias da cidade. Apenas um mês depois de sua morte, 
168 pessoas foram formalmente acusadas de conspirar com ele para "dificultar a aplicação de certas leis nos Estados Unidos”. Elizabeth Gurley Flynn era a única mulher entre eles.

A julgar por sua biografia, The rebel girl, o intenso envolvimento com a IWW - organização sindical que representava os Trabalhadores Industriais do Mundo - reforçava a necessidade de lutar não apenas por melhores salários e condições de trabalho para as operárias e os operários brancos, mas também por pautas que tivessem como foco o fim da discriminação sexual e racial, sobretudo, contra as mulheres negras. Pelo fato de a quase totalidade dessa população ainda trabalhar ou na agricultura ou em funçóes domésticas, sua causa ainda era, em grande medida, invisível aos principais líderes dos movimentos sindicais Mais uma vez, Flynn era exceção entre eles. Tanto que em 1948, em artigo no qual disserta sobre o significado do Dia Internacional da Mulher, ela escreve: "O direito ao trabalho, à formação, à atualização e à valorização por tempo de serviço; meios de proteçáo à saúde e à segurança; creches adequadas: essas continuam a ser as demandas urgentes das mulheres da classe trabalhadora organizada e são necessárias para todas as pessoas que trabalham duro, especialmente as mulheres negras." (FLYNN, apud DAVIS, 2016, p. 169). Ciente do triplo grilhão da opressão imposto a suas irmãs negras, Elizabeth esforçava-se por conscientizar seus companheiros e companheiras do partido a respeito do papel central que a libertação negra desempenhava na luta geral pela emancipação da classe trabalhadora. "Toda desigualdade e limitação impostas à mulher branca estadunidense são agravadas mil vezes entre as mulheres negras, triplamente exploradas - como negras, como trabalhadoras e como mulheres." (FLYNN apud DAVIS, 2016, p. 169).

Fruto de um intenso trabalho junto à comunidade negra comunista, sua amizade com Claudia Jones marca um período extremamente duro, na trajetória de ambas como ativistas comunistas. No auge da "caça às bruxas" decretada pelo governo macartista, as duas são presas e confinadas, primeiro na Casa de Detenção Feminina de Nova York e, mais tarde, no Reformatório Federal Feminino de Alderson, na Virgínia. Apesar do fim legal da segregação, no interior dos presídios, a discriminação racial ainda era flagrante em suas dependências, tanto por parte dos gestores quanto das próprias detentas. Desse modo, as mulheres negras eram invariavelmente designadas para realizar os trabalhos mais duros, na fazenda, na fábrica de conservas, na criação de porcos etc. Não obstante a ascendência irlandesa, Elizabeth reconhece que se sentia mais inclinada a relacionar-se com as mulheres negras, sendo sua solidariedade 
igualmente bem recebida por elas. Como observa Angela Davis, talvez porque estas últimas sentissem nessa comunista branca uma "afinidade instintiva" com a luta comum pela emancipação.

Nascida em Trinidad, quando a ilha ainda fazia parte das Índias Ocidentais Britânicas, Claudia Jones foi uma de suas fiéis companheiras de vida e de luta. Por volta dos vinte anos, tornou-se líder e símbolo de coragem e determinação para as mulheres comunistas de todo o país, ao assumir a responsabilidade pela Comissão de Mulheres do Partido Comunista. Em junho de 1949, essa jovem militante negra publicaria um de seus artigos mais marcantes, na Political Affairs, intitulado "Um fim à negligência aos problemas da mulher". Em seus esforços reiterados pela emancipação da mulher negra, ela chegava frequentemente a repreender seus colegas progressistas - em especial, os sindicalistas - pelo reconhecimento incorreto destinado às trabalhadoras domésticas negras.

Pelo fim da manutenção de atitudes racistas e paternalistas contra as empregadas náo-brancas, Claudia foi precisa e contundente, ao constatar: "Relegar continuamente as mulheres negras ao trabalho doméstico ajudou a perpetuar e intensificar o chauvinismo dirigido contra elas." (JONES apud DAVIS, 2016, p. 172). Mesmo as camaradas brancas não eram poupadas de suas críticas. Como diversas mulheres negras argumentaram antes dela, Jones insistia que o movimento progressista e, sobretudo, as comunistas brancas deveriam assumir uma responsabilidade específica em relação às mulheres negras. Afinal, sendo uma "comunista dedicada", acreditava tenazmente que o socialismo era a única esperança de libertação, não apenas para as mulheres negras, como também para todo o povo negro e para a classe trabalhadora multirracial.

\section{A liberdade é uma luta constante}

Não é, pois, fortuito que Angela Davis conclua o último capítulo de Mulheres, raça e classe, ratificando essa convicção e, ao mesmo tempo, defendendo a necessidade da "abolição das tarefas domésticas enquanto responsabilidade privada e individual das mulheres negras" como um "objetivo estratégico da libertação feminina" (DAVIS, 2016, p. 244). Mais de trinta e cinco anos depois, sua exortação continua valendo - o que indica que ainda há muito a ser feito para que isso aconteça. Portanto, ao lado de Sojouner Truth, Audre Lorde, bell hooks e Patricia Hill Collins - mas também Lélia Gonzales, Beatriz Nascimento, Sueli Carneiro, Djamila Ribeiro e Marielle Franco -, Angela 
Davis assume seu lugar de protagonismo junto aos movimentos sociais transnacionais e ao feminismo negro brasileiro, em particular. Elas e tantas outras mulheres hoje reunidas nessa luta comum são as herdeiras e continuadoras de um "legado de trabalho duro, perseverança e autossuficiência, um legado de tenacidade, resistência e insistência na igualdade sexual [e racial] - em resumo, um legado que explicita os parâmetros para uma nova condição de mulher" (DAVIS, 2016, p. 41). Por tudo isso, Mulheres, raça e classe deve ser lido - e relido! - com a máxima urgência. Ainda.

\section{REFERÊNCIAS}

DAVIS, A. Mulheres, cultura e política. São Paulo: Boitempo, 2017. . A liberdade é uma luta constante. São Paulo: Boitempo, 2018. . Uma autobiografia. São Paulo: Boitempo, 2019.

RIBEIRO, D. O que é lugar de fala? Belo Horizonte: Letramento; Justificando, 2017. 